\title{
Short-term outcomes after repair treatment (clipping or coiling) in aneurysmal subarachnoid hemorrhage (ASAH): a prospective multicenter study
}

\author{
M Gero Escapa 1*, D Iglesias Posadilla', J González Robledo², A Domínguez Berrot ${ }^{3}$, A González Salamanca4, \\ L Nogales Martín ${ }^{5}$, S Ossa Echeverri ${ }^{1}$, A Diego Calvo², M Riesco Crespo ${ }^{3}$, AM Olmos Linares ${ }^{4}$, A Bueno Sacristán ${ }^{5}$, \\ R Ranedo Zaldo ${ }^{1}$
}

From ESICM LIVES 2015

Berlin, Germany. 3-7 October 2015

\section{Introduction}

aSAH is a significant cause of morbidity and mortality, therefore early aneurysm repair treatment, surgical clipping or endovascular coiling, is mandatory to reduce the rate of rebleeding. Determination of treatment should be a multidisciplinary decision based on characteristics of the patient and the aneurysm, however there is variability among the different centers.

\section{Objectives}

Analysis of outcomes and complications in patients with aSAH in regard to election of repair treatment modality and short term therapy.

\section{Methods}

Multicenter, prospective and observational study. Including aSAH patients admitted in five neurocritical care units over 2014. Different variables were analized: morbidity (GOS at discharge), aneurysm location and size, repair treatment, aneurysm obliteration time, complications, ICU and hospital lenght of stay.

\section{Results}

Sample size: 88 patients. Repair treatment: surgical(S) $28,41 \%$, endovascular (EVT) $56,82 \%$ and conservative $14,77 \%$. Morbidity-GOS scale (S/EVT): $1=8 \% / 14 \%$; $2=4 \% / 2 \% ; 3=12 \% / 12 \%$ 4: $28 \% / 14 \%$ 5: 48 \%/ 58\% (p 0,59). We separated 2 GOS groups: good prognosis (grade $3,4,5) 88 \% / 84 \%$ and bad prognosis $(1,2) 12 \% / 16 \%$ (p 0,64). Complications (S/EVT): vasospasm 28\% /22\% (p 0,57); rebleeding $24 \% / 10 \%(\mathrm{p} 0,11)$ and delayed cerebral ischemia (DCI) $16 \% / 34 \%$ (p 0,10). Aneurysm obliteration time (S/EVT): 3,92 days (SD 6,48) / 4,82 (SD 15,75) (p 0,79). Analysis of complications with short term therapy: $<72 \mathrm{~h} / \geq 72 \mathrm{~h}(72,97 \% / 27,03 \%)$ : vasospasm $24,07 \%$ /20\% (p 0,711); rebleeding 9,26\%/30\% (p 0,026) and delayed cerebral ischemia (DCI) 25,93\%/30\% (p 0,726). Aneurysm location and treatment (S/EVT): anterior comunicant 5,48\%/ 28,77\%; posterior 9,59 \%/ 12,33\%; middle cerebral artery $13,70 \% / 13,70 \%$, basilar 1,37\%/ $2,74 \%$ and other $4,11 \% / 8,22 \%$. Aneurysmal sack diameter: small $(<15 \mathrm{~mm}$ ) 27,78\%/44,44\%, large 4,17\%/16,67\% and giant $(>25 \mathrm{~mm}$ ) 1,39\%/5,56\%. Length of stay (S/EVT): ICU 26,32 (SD 4,54)/14,04 (SD 2,67) days (p 0,016) and hospital $36,8(\mathrm{SD} 6,04) / 23,7$ (SD 3,17) days (p 0,04).

\section{Conclusions}

EVT grows up in the analyzed centers. In this study differences about outcomes and complications are not found in regard to repair treatment. In surgical patients rebleeding increases and in EVT DCI is greater. Short term therapy $(<72 \mathrm{~h})$ decreases rebleeding. There is statistical significance in lenght of stay (ICU and hospital) decreases in EVT patients.

Hospital Universitario de Burgos, Burgos, Spain

Full list of author information is available at the end of the article 


\section{Authors' details}

${ }^{1}$ Hospital Universitario de Burgos, Burgos, Spain. ${ }^{2}$ Complejo Asistencial Universitario de Salamanca, Salamanca, Spain. ${ }^{3}$ Complejo Asistencial Universitario de León, León, Spain. ${ }^{4}$ Hospital Universitario Río Hortega, Valladolid, Spain. ${ }^{5}$ Hospital Clínico Universitario de Valladolid, Valladolid, Spain.

Published: 1 October 2015

\section{References}

1. Sander E, Connolly, et al: Guidelines for the Management of Aneurysmal Subarachnoid Hemorrhage. Stroke 2012, 43:1711-1737.

2. Lagares A, et al: Variability in the management of aneurysmal subarachnoid haemorrhage in Spain: Analysis of the prospective multicenter database from the Working Group on Neurovascular Diseases of the Spanish Society of Neurosurgery. Neurocirugía 2015.

3. Joanna $D$, et al: Long-Term recurrent Subarachnoid Hemorrhage after adequate coiling Versus clipping of ruptured intracranial aneurysms. Stroke 2009, 40:1758-1763.

doi:10.1186/2197-425X-3-S1-A781

Cite this article as: Gero Escapa et al:: Short-term outcomes after repair treatment (clipping or coiling) in aneurysmal subarachnoid hemorrhage (ASAH): a prospective multicenter study. Intensive Care Medicine

Experimental 2015 3(Suppl 1):A781.

\section{Submit your manuscript to a SpringerOpen ${ }^{\mathcal{O}}$ journal and benefit from:}

- Convenient online submission

- Rigorous peer review

- Immediate publication on acceptance

- Open access: articles freely available online

- High visibility within the field

- Retaining the copyright to your article 